\title{
Soluble purified recombinant C2ORF40 protein inhibits esophageal cancer cell proliferation by inducing cell cycle $G_{1}$ phase block
}

\author{
XIAOYAN LI ${ }^{1 *}$, LINWEI LI ${ }^{1 *}$, WENYU WANG ${ }^{1}$, YANG YANG ${ }^{2}$, YUN ZHOU $^{1}$ and SHIXIN LU ${ }^{2}$ \\ ${ }^{1}$ Department of Oncology, Zhengzhou University People's Hospital, Zhengzhou, Henan 450003; \\ ${ }^{2}$ State Key Laboratory of Molecular Oncology and Department of Etiology and Carcinogenesis, Cancer Institute and Hospital, \\ Chinese Academy of Medical Sciences and Peking Union Medical College, Beijing 100021, P.R. China
}

Received October 7, 2014; Accepted June 11, 2015

DOI: $10.3892 / \mathrm{ol} .2015 .3429$

\begin{abstract}
Chromosome 2 open reading frame 40 (C2ORF40) plays a significant role in numerous processes, including cell differentiation, senescence, apoptosis, inflammation and neuroendocrine hormone regulation. Moreover, C2ORF40 is a candidate tumor suppressor gene in a variety of tumors, and is closely associated with prognosis. Bioinformatics analysis has indicated that pro-C2ORF40 is a secreted protein with a signal peptide. Secreted C2ORF40 protein (sC2ORF40) exists in cancer cell medium. However, thus far, the exact biological function of sC2ORF40 in carcinogenesis has not been thoroughly researched. In the present study, the signal peptide sequence of the C2ORF40 complementary DNA was initially cut off to produce secreted recombinant human C2ORF40 protein (rhC2ORF40). The soluble rhC2ORF40 was expressed, purified and examined for tumor-suppressing function for the first time. The results revealed that the soluble purified rhC2ORF40 protein was concentrated with a purity of $>95 \%$. Furthermore, the rhC2ORF40 inhibited esophageal cancer cell proliferation in vitro $(\mathrm{P}<0.05)$ and caused cell cycle $\mathrm{G}_{1}$ phase block, as determined by flow cytometric analysis
\end{abstract}

Correspondence to: Dr Linwei Li, Department of Oncology, Zhengzhou University People's Hospital, 7 Weiwu Road, Zhengzhou, Henan 450003, P.R. China

E-mail: lilinweillw@126.com

Professor Shixin Lu, State Key Laboratory of Molecular Oncology and Department of Etiology and Carcinogenesis, Cancer Institute and Hospital, Chinese Academy of Medical Sciences and Peking Union Medical College, 17 Panjiayuan Street, Beijing 100021, P.R. China

E-mail: shlu@public.bta.net.cn

${ }^{*}$ Contributed equally

Key words: rhC2ORF40, purification, cell proliferation, biological therapy
$(\mathrm{P}<0.05)$. Overall, the soluble rhC2ORF40 protein with high purity and biological activity was obtained, which suppressed esophageal cancer cells proliferation by inducing cell cycle $\mathrm{G}_{1}$ phase block in vitro. Therefore, the soluble rhC2ORF40 protein could be potential biological therapy drug for esophageal carcinoma.

\section{Introduction}

Esophageal carcinoma ranks in the forefront of cancers in terms of incidence and mortality rate in males and females in developing countries (1). Moreover, almost $50 \%$ of the world's cases of esophageal cancer occur in China. As the most common histological subtype, esophageal squamous cell carcinoma (ESCC) accounts for around $90 \%$ of all esophageal cancers that are diagnosed in China each year. To date, the molecular pathogenesis of ESCC remains unclear. The current focus of biological studies is the transition from novel gene cloning to the characterization of protein product function (2). As a result, a considerable research effort has been directed at novel specific esophageal cancer-associated proteins in order to identify their functions and identify the relevant molecular mechanisms for carcinogenesis in ESCC.

Human chromosome 2 open reading frame 40 (C2ORF40; also known as ECRG4) has been shown to be expressed in a variety of tissues, including the heart, placenta, brains, lungs, skeletal muscle, liver, kidneys and pancreas (3). Recent studies showed that C2ORF40 was important in a number of processes, including cell differentiation, senescence, apoptosis, inflammation and neuroendocrine hormone regulation (4-6). Moreover, a variety of studies revealed that C2ORF40 was a candidate tumor suppressor gene that is associated with prognosis in multi-tumors (7-9). C2ORF40 was an independent prognostic factor for ESCC, and low C2ORF40 expression in ESCC patients was associated with a poor prognosis $(9,10)$. Our previous results demonstrated that $C 2 O R F 40$ was highly expressed in the adult esophageal epithelia, but that it was downregulated in ESCC tissues and cell lines (9). Furthermore, C2ORF40 transfection inhibited cancer cell growth and invasion (9,11-13). Bioinformatics analysis indicated that pro-C2ORF40 protein was a secreted protein with a signal 
peptide. Therefore, the C2ORF40 protein could be secreted into cell medium to function biologically. However, the exact biological function of secreted C2ORF40 (sC2ORF40) protein in carcinogenesis has not been thoroughly researched in ESCC thus far.

The present study initially cloned and expressed soluble recombinant human C2ORF40 protein (rhC2ORF40), validated the tumor-suppressing biological activities of rhC2ORF40 protein and investigated the possible molecular mechanism for growth inhibition in ESCC.

\section{Materials and methods}

Production and purification of soluble recombinant human C2ORF40 protein. Cut-short rhC2ORF40 complementary (c)DNA (1-28 signal peptide sequence was deleted) was excised from preserved pGEM-T-C2ORF40 (constructed and preserved by the State Key Laboratory of Molecular Oncology and Department of Etiology and Carcinogenesis, Cancer Institute and Hospital, Chinese Academy of Medical Sciences and Peking Union Medical College, Beijing, China) and subcloned into the pET30a(+) plasmid, producing an inducible expression vector, pET30a-C2ORF40, coding for His-tagged soluble rhC2ORF40 protein (without signal peptide). The primers were as follows: Forward, 5'-TCGGATCCATAAGTGGAAATAACTC-3'; and reverse, 5'-TCAAGCTTTTAGTAGTCATCGTAGTT-3'. Thermal cycles were as follows: $95^{\circ} \mathrm{C}$ for $5 \mathrm{~min}$, then 35 cycles at $95^{\circ} \mathrm{C}$ for $30 \mathrm{sec}, 55^{\circ} \mathrm{C}$ for $30 \mathrm{sec}$ and $72^{\circ} \mathrm{C}$ for $45 \mathrm{sec}$, followed by extension at $72^{\circ} \mathrm{C}$ for $7 \mathrm{~min}$. The polymerase chain reaction (PCR) product was digested by BamHI and HindIII. Subsequently, the recombinant plasmids were transformed into Escherichia coli BL21 (DE3) cells to produce N-terminal His-tagged soluble rhC2ORF40 protein. Recombinant rhC2ORF40 protein expression in Escherichia coli BL21 cells was induced with $0.3 \mathrm{mM}$ isopropyl $\beta$-D-1-thiogalactopyranoside and detected by SDS-PAGE and western blotting. Next, the rhC2ORF40 protein was purified and renatured by affinity chromatography with nickel-nitrilotriacetic acid resin (Novagen, Merck Millipore, Darmstadt, Germany) according to the manufacturer's instructions. The purified recombinant rhC2ORF40 protein was dialyzed in phosphate-buffered saline [PBS; $0.1 \mathrm{M}$ sodium phosphate and $0.15 \mathrm{M}$ sodium chloride $(\mathrm{pH} 7.4)$ ] to remove the denaturant. The recombinant soluble rhC2ORF40 protein was used for functional experiments.

Cell proliferation assay. The human esophageal squamous EC9706 cell line was studied. The EC9706 cells were seeded into 96 -well plates $\left(1.5 \times 10^{3}\right.$ cells/well). Different concentrations of rhC2ORF40 protein $(1.5,3.0,4.5,6.0,7.5,9.0$ and $10.5 \mu \mathrm{g} / \mathrm{ml}$ ) were added to each well and cultured for $48 \mathrm{~h}$, and cell proliferation inhibition was evaluated by thiazolyl blue tetrazolium bromide (MTT) assay, according to the manufacturer's instructions (Sigma-Aldrich, St. Louis, MO, USA). In brief, $10 \mu \mathrm{l}$ MTT solution $(5 \mathrm{mg} / \mathrm{ml})$ was added to each well, then the cells were cultured for another $4 \mathrm{~h}$ at $37^{\circ} \mathrm{C}$, and $100 \mu \mathrm{l}$ DMSO was added to each well and mix vigorously to solubilize colored crystals produced within the living cells. The absorbance at $570 \mathrm{~nm}$ was measured by using a multi-well scanning spectrophotometer (Victor 3; PerkinElmer, Waltham,
MA, USA). Cell growth curves for treatment with $10 \mu \mathrm{g} / \mathrm{ml}$ rhC2ORF40 protein or PBS for various durations $(1,2,3,4$ and 5 days) were also plotted by MTT assay. The mean values for statistical analysis represented the mean of three independent experiments.

Flow cytometric analysis of the cell cycle. The EC9706 cells were seeded at a density of $10^{6}$ cells/100-mm dish in RPMI-1640 medium with $10 \%$ FBS and treated with $10 \mu \mathrm{g} / \mathrm{ml}$ rhC2ORF40 or PBS for $48 \mathrm{~h}$. Next, the cells were washed with ice-cold PBS, harvested and fixed in $70 \%$ ethanol for $30 \mathrm{~min}$. The cells were treated with RNase A and stained with $25 \mu \mathrm{g} / \mathrm{ml}$ propidium iodide. Samples were analyzed using a FACScan flow cytometer (BD Biosciences, Franklin Lakes, NJ, USA), according to the manufacturer's instructions. Experiments were performed three times in triplicate.

Statistical analysis. All statistical analyses were performed with the SPSS statistical program (version 16.0; SPSS, Inc., Chicago, IL, USA). Statistical significance was determined using Student's t-test and an analysis of variance. $\mathrm{P}<0.05$ was considered to indicate a statistically significant difference.

\section{Results}

C2ORF40 protein is a secreted protein. C2ORF40 protein is a secreted protein with a signal peptide upon Swiss-Prot Protein Sequence Database Bioinformatics analysis (http://web.expasy.org/docs/swiss-prot_guideline.html). It was discovered that the SC2ORF40 protein existed in EC9706 cancer cell medium transfected with C2ORF40 plasmid compared with the control group, as determined by western blot analysis (data not shown). Therefore, C2ORF40 protein could be secreted into the extracelluar environment to function biologically.

Production of purified rhC2ORF40 protein. In the present study, the signal peptide sequence of the $C 2 O R F 40$ cDNA was cut off to produce secreted rhC2ORF40 protein. The constructed plasmid, pET30a-C2ORF40, was identified by PCR restrictive enzyme digestion (Fig. 1A) and DNA sequencing (data not shown). Next, recombinant BL21 strains that expressed rhC2ORF40 protein were obtained (Fig. 1B). The rhC2ORF40 protein was specifically recognized by the anti-His and anti-C2ORF40 antibodies (Fig. 1C). The rhC2ORF40 protein was purified, with a purity of $>95 \%$ (Fig. 1D).

rhC2ORF40 inhibits tumor cell proliferation. The purified rhC2ORF40 protein was produced to test its biological tumor-suppressing activity in ESCC. MTT assay showed that rhC2ORF40 protein markedly inhibited EC9706 cell proliferation with high potency in a dose-dependent manner (Fig. 2A). The half maximal inhibitory concentration $\left(\mathrm{IC}_{50}\right)$ of the rhC2ORF40 protein was $\sim 10 \mu \mathrm{g} / \mathrm{ml}$, and the growth curves demonstrated that the EC9706 cells treated with $10 \mu \mathrm{g} / \mathrm{ml}$ rhC2ORF40 grew more slowly than those in the PBS control group $(\mathrm{P}<0.05)$, as shown by MTT assay (Fig. 2B).

rhC2ORF40 blocks cell cycle progression. Cell cycle analysis was performed by flow cytometry, and the result suggested that rhC2ORF40 could arrest the ESCC cells at the $\mathrm{G}_{1} / \mathrm{S}$ checkpoint 
Table I. rhC2ORF40 causes cell cycle $\mathrm{G}_{1}$ phase block.

Relative cell number ratio

\begin{tabular}{lccr}
\cline { 2 - 4 } Group & $\mathrm{G}_{1}$ & $\mathrm{~S}$ & $\mathrm{G}_{2} / \mathrm{M}$ \\
\hline rhC2ORF40-treated $^{\mathrm{a}}$ & $73.6 \pm 1.79$ & $14.7 \pm 1.20$ & $11.7 \pm 0.98$ \\
Control & $60.1 \pm 2.11$ & $24.5 \pm 1.53$ & $15.4 \pm 1.67$
\end{tabular}

${ }^{\text {a }}<0.05$ vs. control group. rhC2ORF40, recombinant human chromosome 2 open reading frame 40.

$\mathbf{A}$

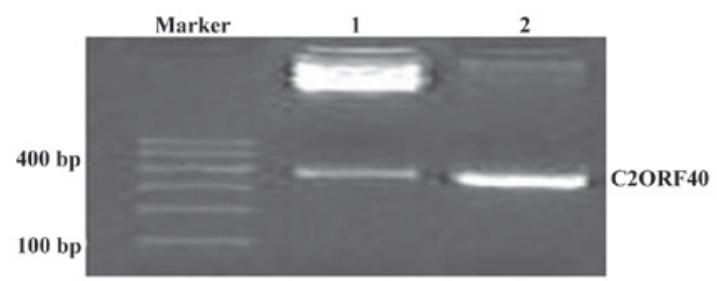

B

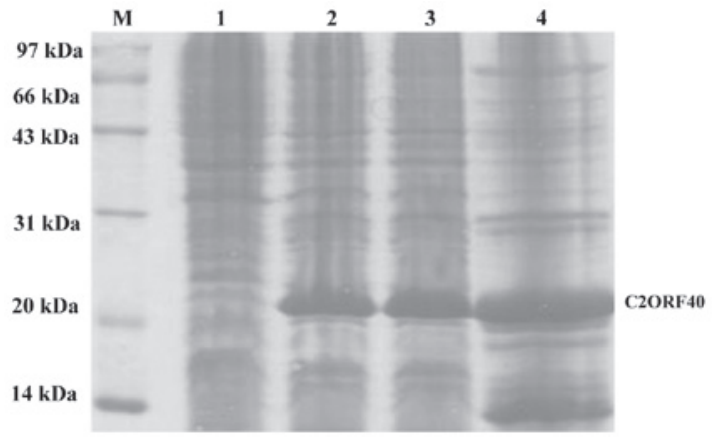

C

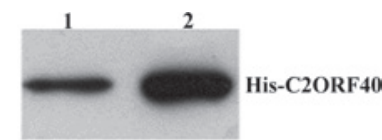

D

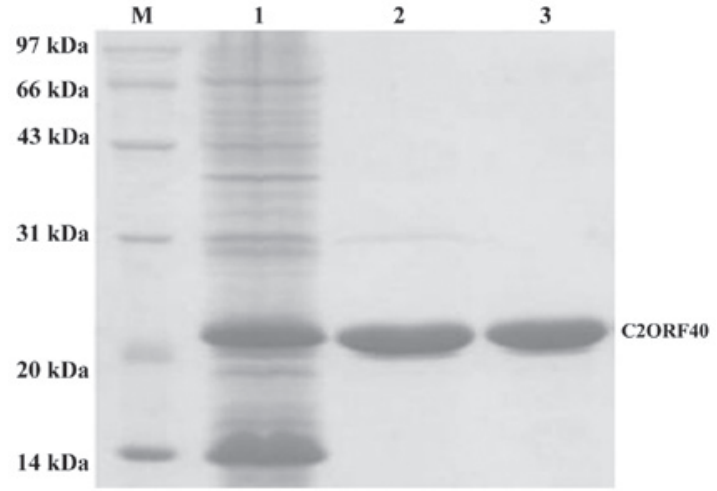

Figure 1. Production and purification of recombinant human chromosome 2 open reading frame 40 (rhC2ORF40) protein. (A) Production of rhC2ORF40 DNA and electrophoresis analysis of rhC2ORF40 complementary (c)DNA by polymerase chain reaction (PCR) and restrictive enzyme digestion. Lane 1, pET30a-C2ORF40 was digested by BamHI and HindIII; lane 2, PCR product of $\mathrm{C} 2 \mathrm{ORF} 40 \mathrm{cDNA}$ from pET30a-C2ORF40. (B) SDS-PAGE analysis of the total proteins of recombinant BL21. Lane 1, BL21 transfected with empty plasmid pET30a; lane 2, BL21 transfected with pET30a-C2ORF40; lane 3, the lysate deposit of BL21 transfected with pET30a-C2ORF40; lane 4, the lysate supernatant of BL21 transfected with pET30a-C2ORF40. (C) Recombinant rhC2ORF40 protein was detected in BL21 transfected with pET30a-C2ORF40 by western blotting (lane 1, anti-C2ORF40; lane 2, anti-His). The BL21 transfected with empty plasmid pET30a was used as a negative control, and it demonstrated no C2ORF40 protein expression. (D) SDS-PAGE analysis of the purified rhC2ORF40 protein. Lane 1, the supernatant protein of BL21 transfected with pET30a-C2ORF40; lane 2, rhC2ORF40 protein was purified; lane 3, final purified rhC2ORF40 protein with a purity of $>95 \%$. M, marker.
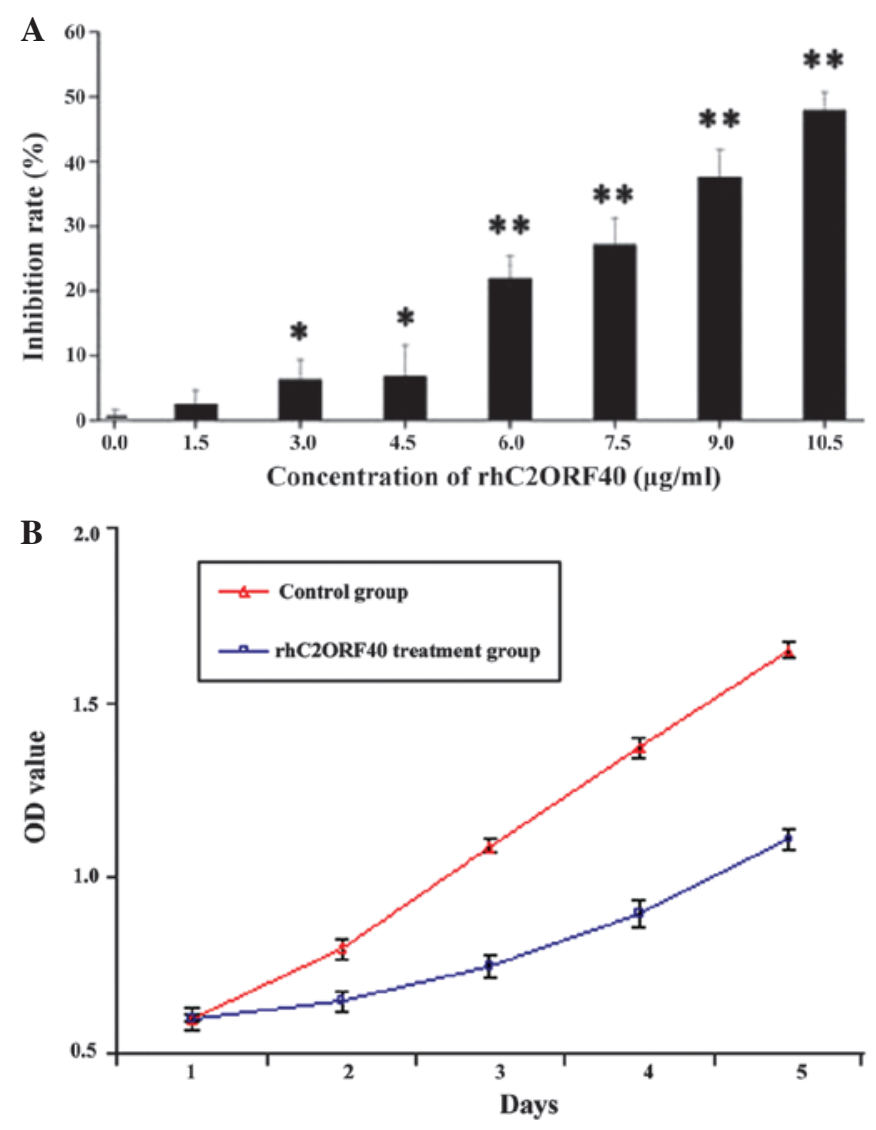

Figure 2. Effect of recombinant human chromosome 2 open reading frame 40 (rhC2ORF40) protein on tumor cells proliferation in vitro. (A) EC9706 cell proliferation was selectively inhibited by the rhC2ORF40 protein. ${ }^{*} \mathrm{P}<0.05$ vs. control group; ${ }^{* *} \mathrm{P}<0.01$ vs. control group. (B) Cell growth curves of EC9706 cells with control treatment (phosphate-buffered saline) or $10 \mu \mathrm{g} / \mathrm{ml}$ rhC2ORF40 treatment $(\mathrm{P}<0.05)$. Error bars represent the standard deviation from the mean.

and delay the transition of the cell cycle into the $S$ phase (Table I), which was consistent with our previous C2ORF40 gene transfection result (4). Consequently, rhC2ORF40 protein slowed down cell cycle progression, and caused cell cycle $\mathrm{G}_{1}$ phase block.

\section{Discussion}

ESCC is a highly invasive and clinically challenging cancer. Although advances have been made towards a clinically comprehensive treatment, the prognosis of ESCC remains poor due to its diffuse and invasive nature (1). Novel 
biological therapy drugs with high antitumor efficacy are being constantly sought to improve the survival of patients with ESCC. In the present study, it was observed that rhC2ORF40 protein inhibited tumor cell growth by inducing cell cycle $\mathrm{G}_{1}$ phase block in vitro, which was consistent with the results of our previous C2ORF40 gene transfection study in $\operatorname{ESCC}(9,11,14)$. Therefore, the soluble rhC2ORF40 protein with high purity and biological activity was obtained. In vivo functional experiments require further study to prove that the soluble rhC2ORF40 protein could be a candidate biological therapy drug for esophageal carcinoma.

Transformed cells acquire a series of additional malignant traits during ESCC development and progression. Among them, the alteration to the cell cycle plays a major role in carcinogenesis. Tumorigenesis can be a consequence of an imbalance in cell cycle regulation. Moreover, it has been demonstrated that numerous oncogenes and tumor suppressor genes are directly involved in the regulation of cell cycle events. Of these, the p21 and p16 genes, which are critical cyclin-dependent kinase inhibitors, were believed to hold functional relevance with regard to the regulation of the cell cycle $G_{1}$ phase. Our previous study result demonstrated that C2ORF40 transfection induced upregulation of $p 21$ expression in ESCC cells $(11,14)$. However, there was no significant upregulation of p16 expression level in the ESCC cells (data not shown). Therefore, the increased expression of $p 21$, but not p16, was likely to be responsible for the cell cycle $\mathrm{G}_{1}$ phase block induced by C2ORF40 in ESCC $(11,14)$.

Transmembrane protease serine 11A (TMPRSS11A; also known as ECRG1) is a novel candidate tumor suppressor gene that has been shown to be important in the control of gene expression for those genes involved in cell cycle $\mathrm{G}_{1}$ phase arrest in ESCC. In pervious studies, TMPRSS11A gene overexpression inhibited tumor cell growth in vitro and in vivo (15), and induced cell cycle $G_{1}$ phase arrest and cell senescence (16) in ESCC. As C2ORF40 is a putative pro-hormone protein (also known as augurin) $(17,18)$, it may be a good candidate substrate for the transmembrane serine protease TMPRSS11A in ESCC. We previously found that C2ORF40 could directly bind to TMPRSS11 A in ESCC cells, as determined by binding affinity assay and co-immunoprecipitation experiments (14). C2ORF40 was able to cause cell cycle $\mathrm{G}_{1}$ phase block by interaction with TMPRSS11A in ESCC (14). However, the detailed molecular mechanism remains to be clarified.

In the present study, the soluble rhC2ORF40 protein with high purity and biological activity was obtained, which suppressed tumor cell growth by inducing cell cycle $\mathrm{G}_{1}$ phase block in vitro in ESCC. These results indicate that soluble rhC2ORF40 protein could be a potential biological therapeutic drug for ESCC.

\section{Acknowledgements}

This study was supported by the Chinese National Natural Science Foundation (grant no. U1304817) and the Zhengzhou City Science Research Project (grant no. 141PPTGHG298).

\section{References}

1. Jemal A, Bray F, Center MM, Ferlay J, Ward E and Forman D: Global cancer statistics. CA Cancer J Clin 61: 69-90, 2011.

2. Eisenberg D, Marcotte EM, Xenarios I and Yeates TO: Protein function in the post-genomic era. Nature 405: 823-826, 2000.

3. Steck E, Breit S, Breusch SJ, Axt M and Richter W: Enhanced expression of the human chitinase 3-like 2 gene (YKL-39) but not chitinase 3-like 1 gene (YKL-40) in osteoarthritic cartilage. Biochem Biophys Res Commun 299: 109-115, 2002.

4. Kujuro Y, Suzuki N and Kondo T: Esophageal cancer-related gene 4 is a secreted inducer of cell senescence expressed by aged CNS precursor cells. Proc Natl Acad Sci USA 107: 8259-8264, 2010.

5. Huh YH, Ryu JH, Shin S, Lee DU, Yang S, Oh KS, Chun CH, Choi JK, Song WK and Chun JS: Esophageal cancer related gene 4 (ECRG4) is a marker of articular chondrocyte differentiation and cartilage destruction. Gene 448: 7-15, 2009.

6. Matsuzaki J, Torigoe T, Hirohashi Y, Kamiguchi K, Tamura Y, Tsukahara T, Kubo T, Takahashi A, Nakazawa E, Saka E, et al: ECRG4 is a negative regulator of caspase-8-mediated apoptosis in human T-leukemia cells. Carcinogenesis 33: 996-1003, 2012.

7. Lu J, Wen M, Huang Y, He X, Wang Y, Wu Q, Li Z, Castellanos-Martin A, Abad M, Cruz-Hernandez JJ, et al: C2ORF40 suppresses breast cancer cell proliferation and invasion through modulating expression of $\mathrm{M}$ phase cell cycle genes. Epigenetics 8: 571-583, 2013.

8. Götze S, Feldhaus V, Traska T, Wolter M, Reifenberger G, Tannapfel A, Kuhnen C, Martin D, Müller O and Sievers S: ECRG4 is a candidate tumor suppressor gene frequently hypermethylated in colorectal carcinoma and glioma. BMC Cancer 9: 447, 2009

9. Li LW, Yu XY, Yang Y, Zhang CP, Guo LP and Lu SH: Expression of esophageal cancer related gene 4 (ECRG4), a novel tumor suppressor gene, in esophageal cancer and its inhibitory effect on the tumor growth in vitro and in vivo. Int J Cancer 125: 1505-1513, 2009

10. Mori Y, Ishiguro H, Kuwabara Y, Kimura M, Mitsui A, Kurehara H, Mori R, Tomoda K, Ogawa R, Katada T, et al: Expression of ECRG4 is an independent prognostic factor for poor survival in patients with esophageal squamous cell carcinoma. Oncol Rep 18: 981-985, 2007.

11. Li LW, Zhang CP, Li XY, Lu S and Zhou Y: The candidate tumor suppressor gene ECRG4 inhibits cancer cells migration and invasion in esophageal carcinoma. J Exp Clin Cancer Res 29: $133,2010$.

12. Xu T, Xiao D and Zhang X: ECRG4 inhibits growth and invasiveness of squamous cell carcinoma of the head and neck in vitro and in vivo. Oncol Lett 5: 1921-1926, 2013.

13. Li W, Liu XR, Zhang B, Qi D, Zhang L, Jin Y and Yang H: Overexpression of candidate tumor suppressor ECRG4 inhibits glioma proliferation and invasion. J Exp Clin Cancer Res 29: 89, 2010.

14. Li LW, Li YY,LiXY,Zhang CP,Zhou Y and Lu SH: A novel tumor suppressor gene ECRG4 interacts directly with TMPRSS11A (ECRG1) to inhibit cancer cell growth in esophageal carcinoma. BMC Cancer 11: 52, 2011.

15. Yueying W1, Jianbo W, Hailin L, Huaijing T, Liping G and Shih-Hsin L: ECRG1, a novel esophageal gene, cloned and identified from human esophagus and its inhibition effect on tumors. Carcinogenesis 29: 157-160, 2008.

16. Zhao N, Huang G, Guo L and Lu SH: ECRG1, a novel candidate of tumor suppressor gene in the esophageal carcinoma, triggers a senescent program in NIH3T3 cells. Exp Biol Med (Maywood) 231: 84-90, 2006.

17. Baird A, Coimbra R, Dang X, Lopez N, Lee J, Krzyzaniak M, Winfield R, Potenza B and Eliceiri BP: Cell surface localization and release of the candidate tumor suppressor Ecrg4 from polymorphonuclear cells and monocytes activate macrophages. J Leukoc Biol 91: 773-781, 2012.

18. Dang X, Podvin S, Coimbra R, Eliceiri B and Baird A: Cell-specific processing and release of the hormone-like precursor and candidate tumor suppressor gene product, Ecrg4. Cell Tissue Res 348: 505-514, 2012. 